\title{
Development and partial characterization of new marine cell line from brain of Asian sea bass Lates calcarifer for virus isolation
}

\begin{abstract}
A new cell line, Asian sea bass brain (ASBB), was derived from the brain tissue of Asian sea bass Lates calcarifer. This cell line was maintained in Leibovitz L-15 media supplemented with $10 \%$ fetal bovine serum (FBS). The ASBB cell line was subcultured more than 60 times over a period of $15 \mathrm{mo}$. The ASBB cell line consists predominantly of fibroblastic-like cells and was able to grow at temperatures between $20^{\circ} \mathrm{C}$ and $30^{\circ} \mathrm{C}$ with an optimum temperature of $25^{\circ} \mathrm{C}$. The growth rate of these cells increased as the proportion of FBS increased from $2 \%$ to $20 \%$ at $25^{\circ} \mathrm{C}$ with optimum growth at the concentrations of $10 \%$ or $15 \%$ FBS. Polymerase chain reaction products were obtained from ASBB cells and tissues of sea bass with primer sets of microsatellite markers of sea bass. An isolate of piscine nodavirus from juveniles of marine fish species tested positive by IQ2000 kit for viral nervous necrosis detection and was examined for its infectivity to a fish cell line of ASBB. A marine fish betanodavirus was tested to determine the susceptibility of this new cell line in comparison with commercial highly permissive SSN-1 cells. The ASBB cell line was found to be susceptible to nodavirus (RGNNV genotype), and the infection was confirmed by comparison cytopathic effect (CPE) with commercial SSN-1 and reverse transcriptase-polymerase chain reaction. A nodavirus was further elucidated by electron microscopy, and the virus tested was shown to induce CPE on ASBB cells with significant high titer. This suggests that the ASBB cell line has good potential for the isolation of fish viruses.
\end{abstract}

Keyword: Cell line, Asian sea bass, Lates calcarifer, Brain, SSN-1- CPE 